\title{
1913 : la réécriture du concert Saint-Euverte sur les placards de Du côté de chez Swann
}

\section{Françoise Leriche}

\section{(2) OpenEdition}

\section{Journals}

Édition électronique

URL : http://journals.openedition.org/genesis/1153

DOI : 10.4000/genesis. 1153

ISSN : 2268-1590

\section{Éditeur :}

Presses universitaires de Paris Sorbonne (PUPS), Société internationale de génétique artistique littéraire et scientifique (SIGALES)

\section{Édition imprimée}

Date de publication : 15 juin 2013

Pagination : 113-133

ISBN : 978-2-84050-893-9

ISSN : 1167-5101

\section{Référence électronique}

Françoise Leriche, « 1913 : la réécriture du concert Saint-Euverte sur les placards de Du côté de chez Swann », Genesis [En ligne], 36 | 2013, mis en ligne le 08 novembre 2016, consulté le 19 avril 2019. URL : http://journals.openedition.org/genesis/1153; DOI : 10.4000/genesis.1153 


\title{
1913 : la réécriture du concert Saint-Euverte sur les placards de Du côté de chez Swann
}

\author{
Françoise Leriche
}

\begin{abstract}
[L] a partie que j'aime [le mieux] commence justement après [l]e $45^{\mathrm{e}}$ placard. (Et c' est pour cela que je n' ai pu encore me résoudre à la renvoyer à Grasset. (Il [y] en a 95 en tout, mais je trouve que c' est trop long et j' arrêterai le volume plus tôt.)

À Louis de Robert, [peu après le 19 juin 1913] ${ }^{1}$
\end{abstract}

$\mathrm{U}$ mois après avoir renvoyé à son éditeur les quarante-cinq premiers placards du premier volume corrigés ${ }^{2}$, pourquoi Proust ne peut-il toujours pas «se résoudre » à se séparer de la partie finale d' «Un amour de Swann », celle qui commence avec la soirée chez la marquise de Saint-Euverte, au placard 45 ? L'argument de la tomaison (Proust a expliqué à Grasset qu'il lui fallait attendre d'avoir reçu la totalité de ses placards pour savoir le nombre exact de pages imprimées que représentait la dactylographie de son premier tome, avant de décider où il pourrait couper) n'est guère convaincant : c'était la troisième partie du volume qu'il faudrait probablement écourter, mais la deuxième, «Un amour de Swann », qui se termine au placard 52 (soit environ à la page 420), n'était pas concernée par cette question de la césure. Même si Proust avait décidé de couper cette masse de sept cent soixante pages en deux petits volumes vendus ensemble, solution un moment envisagée ${ }^{3}$, on imagine difficilement qu'il eût pratiqué la coupure juste avant le dernier épisode d' "Un amour de Swann ». La raison donnée à Louis de Robert paraît plus plausible : Proust tenait particulièrement à cette soirée Saint-Euverte. Et, ce qu'il ne dit pas à son ami, il était précisément en train d'y opérer d'importantes modifications...

Les soixante et un placards finalement retenus pour $D u$ côté de chez Swann ont presque tous été abondamment corrigés, on le savait, et leur réapparition en 2000 a permis de constater par simple feuilletage le nombre impressionnant d'additions marginales, de becquets, de paperoles, d'interpolations de paragraphes entiers, mais aussi de ratures, de suppressions ${ }^{4}$.

Or, dans ce gigantesque chantier de réécriture, le concert Saint-Euverte - pendant lequel Swann, malheureux et délaissé par Odette, réentend la sonate associée à son amour - devient le lieu d'une réorientation significative du discours esthétique sur la musique, dans une restructuration globale des épisodes musicaux du roman.

Le passage que nous avons retenu ne présente pas de suppressions, mais des additions de deux ordres différents : quelques notations renforçant l'ironie du moraliste ; d'importantes additions qui transforment le discours du roman sur la musique.

1. Marcel Proust, Lettres, p. 622-623.

2. Proust a reçu ses placards d'imprimerie entre le 31 mars et le 11 juin 1913. C'est le 23 mai qu'il a renvoyé ces placards corrigés : voir Corr., t. XIV, p. 381-383 (Lettres, p. 618-619).

3. Solution suggérée à Proust par Louis de Robert, vers la fin juin 1913 (voir Corr., t. XII, p. 219-220, la lettre 98 de L. de Robert à Proust, et p. 224, le post-scriptum de la lettre 100, de Proust à son ami).

4. Longtemps réputés « disparus », les placards corrigés de $D u$ côté de chez Swann sont réapparus en 2000 dans une vente publique et ont été acquis par la Fondation Martin Bodmer (Cologny, Suisse). Pour leur description matérielle, voir Vérène de Soultrait, «Du côté de chez Swann $[\ldots] », B I P$, no $^{\circ} 31,2000$, p. 171-180. 


\section{Le renforcement de la dimension moraliste}

Les modifications ne concernent en effet ni le scénario global de la soirée, ni la fonction cathartique du concert, restés identiques à travers toutes les phases génétiques de l'épisode : remis en présence de la «petite phrase » de la sonate qui était devenue "l'hymne national de son amour » avec Odette, Swann est assailli par les souvenirs de son bonheur et, revivant de façon sensible ces épisodes oubliés, il n'en éprouve que mieux, par comparaison, l'indifférence que lui témoigne désormais Odette cette prise de conscience le menant sur le chemin du détachement. Mais quelques additions et reformulations viennent renforcer de façon ironique le malheur du personnage :

- dans la longue réécriture de la colonne 6 du placard 49 (voir fig. 5), les éléments additionnels soulignent le décalage et l'évolution inverse des désirs respectifs de Swann et Odette (lorsqu'elle manifestait pour lui un désir ardent, il préférait s'en tenir avec elle à une relation galante ; et c'est lorsqu'elle a commencé à s'intéresser à d'autres que, jaloux, il a subordonné à cet amour toutes ses activités) ;

- addition dans la marge gauche, le monocle que Swann ôte et essuie souligne symboliquement son aveuglement, en un contrepoint caustique.

\section{Une modification importante de l'esthétique musicale dans le roman}

Ce qui est le plus notable sur ces placards, c'est la réorientation du discours esthétique sur la musique.

\section{Musique et impressions sensibles}

Dans la réécriture des colonnes 5-6 du placard 49 (voir fig. 4 et 5), l'opposition entre les « expressions abstraites » de la mémoire et l'« essence » du passé vécu se trouve approfondie et subrepticement réorientée en une opposition entre $l^{\prime}$ « intelligence » et « un réseau d'habitudes mentales, d'impressions saisonnières, de réactions cutanées », " réseau uniforme dans lequel son corps se trouvait repris » (je souligne), la petite phrase ramenant ces impressions sensorielles. Alors que le texte initial, biffé, détaillait des scènes principalement visuelles (les pétales de chrysanthème, l'adresse du restaurant sur la lettre, le froncement de sourcils inquiet d'Odette), la réécriture accentue la dimension olfactive (odeur du fer à friser) et les sensations d'humidité, de froid, etc., le passé ainsi revécu dans sa vérité sensorielle ayant toutes les caractéristiques de celui que restitue la mémoire involontaire. Le terme d' "essence » (« il retrouva tout ce qui de ce bonheur avait fixé à jamais la spécifique et volatile essence »), loin de désigner une quelconque abstraction métaphysique, une réalité universelle, signifie ainsi explicitement, chez Proust, un substrat de sensations très individuelles, la qualité existentielle d'un vécu personnel.

Cette coloration individuelle d'expériences universelles (l'amour, la réception d'une œuvre musicale), qui confère à chaque existence sa radicale singularité, est précisément l'élément qui amène Proust en 1913, selon nous, à reconsidérer sa théorie esthétique relative à la musique, et à renforcer de façon perceptible l'idéalisme (schopenhauerien) de Swann afin de ménager, dans la suite du roman, l'espace d'un autre discours, qui sera attribué au protagoniste 5 .

Le texte initial (bas de la col. 8, plac. 49) affirmait, à propos de la musique : «Mais ces idées d'un autre monde, d'un autre ordre que sont les motifs musicaux, idées voilées de ténèbres, inconnues, impénétrables à l'intelligence, n'en sont pas moins entre elles parfaitement distinctes les unes des autres [etc.] ». L'instance narratrice assumait ainsi

5. Anne Henry avait souligné, en l'imputant à l'inconséquence philosophique de Proust, l'incompatibilité théorique qui existe entre la conception schopenhauerienne de la musique dans « Un amour de Swann », et la poétique des «phrases-types » de Vinteuil dans La Prisonnière, inspirée par la théorie des motifs obsédants de Walter Pater pour les arts plastiques (voir Marcel Proust. Théories pour une esthétique, Paris, Klincksieck, 1981, p. 302 sq.), attribuant les divers discours esthétiques du roman à l'auteur lui-même. Pour une analyse qui différencie les discours de Swann et du héros, et un parcours génétique qui montre comment, entre 1911 et 1913, Proust a transféré au personnage de Swann cette conception schopenhauerienne de la musique qui était celle de l'instance narratrice dans les brouillons entre 1910-1911, voir F. Leriche, « La question de la représentation dans la littérature moderne : Huysmans-Proust », thèse de doctorat de l'Université Paris VII, 1991, II ${ }^{\mathrm{e}}$ partie ; ou « La théorie esthétique proustienne à l'épreuve de la génétique », dans Bernard Brun et Juliette Hassine (dir.), Proust au tournant des siècles, Marcel Proust 4, Paris, Minard, 2004, p. 75-108. 
l'existence en-soi de telles «idées », de ces «millions de touches de tendresse, de passion, de sérénité » simplement « découvertes [c'est-à-dire : dévoilées] par quelques grands artistes » qui « nous rendent le service » de lire plus aisément dans « notre âme ». C'est cet universalisme anthropologique qui se trouve désormais mis en question. Une simple addition en marge de la colonne 8 (« Mais depuis plus d'une année que [...] l'amour de la musique était $[\ldots]$ né en lui, Swann tenait les motifs musicaux pour des idées de véritables Idées », voir fig. 5) suffit à attribuer explicitement à Swann (et non plus à l'instance narratrice) ce propos idéaliste ; on note la correction d' « idées » en " Idées », la majuscule faisant immédiatement référence, pour le lecteur averti, à l'un des concepts majeurs de la philosophie schopenhauerienne de la connaissance 6 . Par le biais de la focalisation interne et du récit de pensée, Proust rejette donc sur l'esthète décadent certains éléments schopenhaueriens encore assumés par la narration dans la dactylographie de 1912. Cette unification ${ }^{7}$ du discours prend valeur de clarification théorique, clarification qui paraît motivée par les réflexions nouvelles que Proust est en train d'élaborer depuis le début de 1913, et qu'il s'agit de " préparer » le roman à accueillir en ménageant entre Swann et le protagoniste une nette distribution des rôles.

\section{La musique, non plus expression de la Nature, mais "création » formelle}

La correspondance et les documents de genèse révèlent qu'entre janvier et avril 1913, Proust assiste à plusieurs concerts, lit des ouvrages sur la musique. Apparaissent alors dans le Carnet 2 des réflexions nouvelles, qui incluent la musique dans le cadre de la théorie poétique que le Contre Sainte-Beuve et les notes du Carnet $1^{8}$ avaient développée pour la littérature et la peinture - une œuvre d'art rend perceptible l'imaginaire particulier d'un artiste. Ainsi, Proust note à propos de Lalo :

affinité qui appelle certaines créatures dans le cerveau d'un certain homme dont elles sont les fées familières (phrases de Lalo dans la Rhapsodie norvégienne pareilles à Namouna) ${ }^{9}$.

Berget, l'auteur de la sonate entre 1911 et 1913 (c'est encore ce nom qui figure, ci-après, au folio $20 \mathrm{r}^{\mathrm{o}} \mathrm{du}$
Carnet 2), n'apparaissait jamais comme personnage dans le roman : ce n'était qu'un nom - on ne savait rien de lui. Il était donc le parfait « révélateur » de cet absolu auquel Swann pensait accéder en écoutant la « divine » petite phrase. La correction en « Vinteuil » partout sur les placards témoigne de la transformation du scénario musical à l'échelle du roman : plutôt que d'inventer un nouveau personnage, Proust transforme le naturaliste de Combray, Vington (dont l'œuvre inachevée devait être complétée et publiée par l'amie de sa fille) en un professeur de musique (rebaptisé d'abord Vindeuil puis Vinteuil) ${ }^{10}$, indice qu'il a prévu, dès avril ou mai 1913 , d'attribuer au compositeur une œuvre posthume qui vérifiera la théorie des «phrases-types ».

Parallèlement, il cherche à transformer la sonate, jusqu'ici œuvre romantique sentimentale, en une œuvre d'avant-garde novatrice sur le plan formel :

Me Cottard n'aime pas la peinture d'Elstir. / Elle dira ces femmes bleues, vertes rouges, et enlaidies, lourdes. De même que pour Berget cela a l'air faux des gens qui s'essayent à des notes. C'est ainsi $\mathrm{q}^{\mathrm{d}}$ on dépouille un poncif ${ }^{11}$.

Cet intérêt pour les révolutions formelles en art, pour la dissonance, paraît contemporain du choc reçu par Proust, le 19 avril 1913, en entendant la sonate pour piano et violon de César Franck interprétée d'une manière qui en renouvelle profondément l'esthétique :

6. L'application de ce concept à la musique est d'ailleurs peu rigoureuse (voir F. Leriche, thèse citée, p. 197 et 114). Proust supprimera à une étape ultérieure cette majuscule incompréhensible pour les non-initiés.

7. Unification avec le discours intérieur de Swann, où la petite phrase est définie comme une "créature surnaturelle » existant réellement, que le compositeur a simplement « captée » (I, p. 345 - je souligne).

8. Carnet 1 , notes sur Barbey d'Aurevilly, fos $35 \mathrm{r}^{\circ}$ à $36 \mathrm{r}^{\mathrm{o}}$, et $44 \mathrm{r}^{\mathrm{o}}$ (Carnets, éd. F. Callu et A. Compagnon, Paris, Gallimard, 2002, p. 92-93 et 106-107) ; sur Thomas Hardy, fo 48 ro, et Mantegna, fos 54 vo-55 ro (ibid., p. 116-117 et 131-132).

9. Carnet 2, fos 18 vo-19 ro (éd. citée, p. 179, transcription revue). La Rhapsodie norvégienne date de 1879, Namouna (musique de ballet), de 1882. Notons que ce ballet, présenté comme une œuvre de la « jeune école », fut mal accueilli par le public.

10. Voir Kazuyoshi Yoshikawa, "Vinteuil ou la genèse du Septuor », Cahiers Marcel Proust 9, Études proustiennes III, 1979, p. 289-347.

11. Carnet 2, fos 19 ro-19 vo et 20 ro (éd. citée, p. 182, transcription revue. Je souligne). 
Grosse émotion ce soir. À peu près mort je suis allé [...] entendre la Sonate de Franck que j'aime tant, non pour entendre Enesco que je n'avais jamais entendu [...]. Or je l'ai trouvé admirable, les pépiements douloureux de son violon, les gémissants appels, répondaient au piano, comme d'un arbre, comme d'une feuillée mystérieuse. C'était une très grande impression. [...] Et il désaffadit et redessine le rondeau [sic] qu'on a l'habitude de jouer en se pâmant sous prétexte qu'il est angélique; [...] il y aurait des choses importantes à dire ${ }^{12}$.

Ce jeu énergique, expressionniste, correspond aux mutations esthétiques de l'avant-guerre (peu après, en mai, les Ballets russes donnaient L'Après-midi d'un faune et Le Sacre du printemps avec le scandale que l'on sait). Changer Berget, le «séraphique » auteur de la sonate, en un Vinteuil hardi inventeur de formes expérimentales mais timide et incompris (à l'exemple de Franck), c'est prendre acte de la modernité en germe dans cette sonate (de 1886). Mais la «petite phrase » souple et gracieuse de Swann ne pouvant guère se transformer en un motif avant-gardiste déroutant, Proust procède « audacieusement » lui aussi en inventant sur le placard 50, pour y faire apparaître les prémisses de cette révolution chromatique (qui triomphera dans le dissonant Septuor), « un long morceau que le pianiste de Madame Verdurin sautait toujours » et que par conséquent Swann n'a jamais entendu :

\footnotetext{
Ô plus grande déeouverte < déeouverte aussi audaeieuse> $<$ audace aussi géniale> peut'être, se disait-il, que tes déeottvertes <celles> d'un Lavoisier, d'un Ampère, eelle d'un Vinteuil l'audace d'un Vinteuil expérimentant, découvrant les lois secrètes d'une force inconnue, et dans son tête à tête avee l'ineonnaissable menant à travers l'inexploré, vers le <seul> but qu'il doit atteindre < néeessaire> < possible> l'attelage invisible auquel il se fie et qu'il n'apercevra jamais (Plac. 50, col. 2, addition marginale, voir fig. 7).
}

Mais ayant situé «Un amour de Swann » dans le contexte des années 1886-1888, Proust ne pouvait sans anachronisme doter ce personnage du recul esthétique, ou de la théorie qui lui permettraient de comprendre pleinement le travail entrepris par le compositeur. Depuis le départ, les rôles sont clairement répartis : c'est au protagoniste du roman qu'il reviendra de mener à son terme l'enquête sur la nature de l'art. Une note du Carnet 2 organise deux voies discursives antithétiques : la théorisation poéticienne de l'essayiste (« nous », présent) et - en addition - un récit focalisé (« on sentait», imparfait) mettant en scène une métaphysique de l'art très « fin de siècle »:

Sonate F[ran]ck / <Le violoniste devenu médium lui prêtait son corps et son archet et on sentait les effluves de l'âme incarnée qui tendait ses bras [...] / Est-ce un oiseau, une fée cet être invisible qui appelle, gémit, répond comme dans/'un arbre voisin Comme Il semble que puisqu'il n'y a pas de paroles ce soit le royaume de la fantaisie, et c'est celui de la nécessité ; nous sommes frappés de l'évidence de ee que la réponse $[\ldots]^{13}$ (voir fig. 2).

L'addition au placard 50 reprend ces divers éléments, glissant dans l'interprétation sentimentale de la musique cette rectification formaliste :

C'était [...] comme s'il n'y avait encore eu qu' eux deux sur la terre, ou plutôt dans ce monde fermé à tout le reste, [...] construit par la logique d'un créateur et où ils ne seraient jamais que tous les deux : cette sonate (Plac. 50, col. 2, addition marginale - je souligne, voir fig. 7).

En insistant sur le fait que cette sonate est une création formelle, un univers clos inventé par un artiste, Proust se ménage la possibilité de faire apparaître ultérieurement, lors d'un autre épisode musical (encore à écrire), une autre œuvre de Vinteuil, et de faire dégager par le héros des ressemblances formelles, telles ces «fées familières » qu'il a repérées entre la Rhapsodie norvégienne et Namouna de Lalo. Ainsi dans le Cahier 57, un épisode rédigé un peu plus tard en vue du Temps retrouvé permet au protagoniste de comparer un Quatuor de Vinteuil avec sa sonate ${ }^{14}$. Mais cette nouvelle compréhension de la musique comme expérimentation formelle et déploiement de l'imaginaire personnel d'un créateur n'est pas donnée à Swann ; Proust le maintient dans l'attitude idéaliste

12. Corr., t. XII, p. 147-148 (soulignement de Proust).

13. Carnet 2, fo 21 vo (éd. citée, p. 184-185, transcription revue).

14. Cahier 57, fos $3 \mathrm{r}^{\circ}, 3 \mathrm{v}^{\circ}, 4 \mathrm{r}^{\circ}$ : voir Matinée chez la princesse de Guermantes. Cahiers du Temps retrouvé, éd. Henri Bonnet et Bernard Brun, Paris, Gallimard, 1982, p. 292-296. 
qu'il lui avait forgée dans les brouillons, entre 1911 et 1913 : conçu sur le modèle scientifique, le travail du compositeur consiste selon lui à découvrir des «lois secrètes » ayant une validité en soi, absolue15. Les diverses additions (plac. 50, col. 2, le violoniste comme « médium »; col. 3, la « cérémonie surnaturelle », la comparaison avec les «tables tournantes ») multiplient les clichés « fin de siècle », soulignant ainsi le contexte symboliste qui constitue l'horizon philosophique et esthétique de Swann.

Quelques indices, quelques questions sans réponse, posent des pierres d'attente auxquelles l'expérience du héros viendra répondre. Ainsi, dans cette addition à la colonne 8 du placard 49 (fig. 5) :

Et la pensée de Swann se porta pour la première fois, dans un élan de pitié et de tendresse vers ce Vinteuil, vers ce frère invisible et plus grand vers eet inconnu <et $>$ sublime qui lui aussi avait dû tant souffrir ; qu'avait pu être sa vie ? au fond de quelles douleurs avait-il puisé cette force de dieu, cette puissance illimitée de créer [?]

apparaît le décalage entre Swann (qui ne pense pas que le vieux professeur de Combray soit le compositeur de la sonate) et le héros du roman (qui, ayant assisté à la scène de Montjouvain - et le lecteur avec lui peut, longtemps après «Un amour de Swann », mesurer quelles ont pu être les souffrances de cet homme). Par ailleurs, ne connaissant que cette sonate, Swann ne peut appréhender le travail du créateur comme le fera le héros dans La Prisonnière ; aussi le dépassement de son égoïste sentimentalité le mène-t-il simplement de la musique à la «pitié » (le Mitleid schopenhauerien, degré le plus élevé du parcours spirituel, qui conduit à l'amour de nos «frères » humains).
Les additions aux placards 49 et 50 ne comportent que peu de ratures, indice que l'écrivain avait mûrement préparé la réécriture de ce concert ${ }^{16}$. Les placards Bodmer ne présentent pas de « révélation » pour le généticien ou l'éditeur, puisque toutes leurs modifications se retrouvent dans le texte imprimé du troisième jeu d'épreuves (NAF 16756)17 ; mais il est émouvant d'avoir enfin accès à cette partie du roman que Proust « aimait le plus », et de «voir » comment, par la simple fusion de deux personnages (Vington/Berget) et l'addition d'un scherzo à la sonate, il reconfigure magistralement l'articulation antérieure des épisodes esthétiques, ce mouvement de déconstruction/recomposition étant une des caractéristiques majeures du « style de genèse » proustien.

15. Unification avec les propos précédents : «Swann sentait que le compositeur s'était contenté, avec ses instruments de musique, de la dévoiler, de la rendre visible » (I, p. 345 - je souligne).

16. Dans le jeu de placards Grasset partiellement corrigés que possède la Bibliothèque nationale de France (NAF 16753), les placards 47-49 et les colonnes 1 à 4 du placard 50 manquent. V. de Soultrait (art. cité, p. 172 et 179) a établi que ces colonnes manquantes se trouvent dans le jeu Bodmer : voir la reconstitution du placard initial ci-jointe (col. 1-4 Bodmer, col. 5-8 BnF). On peut penser que Proust a tellement retravaillé cet épisode du concert Saint-Euverte sur l'un des jeux d'épreuves qu'il a dû utiliser les placards de l'autre jeu comme mise au net, ce qui expliquerait le caractère extrêmement maîtrisé des corrections sur le jeu remis à l'éditeur. (Le prélèvement des colonnes 1 à 4 ayant eu lieu après le travail de correction, comme l'a remarqué Nathalie Mauriac Dyer en reconstituant le document original, reste à savoir pourquoi Proust n'a pas conservé la totalité du placard 50 dans le jeu « au net » et a relégué les colonnes 5 à 8 dans le reliquat.)

17. En comparant les troisièmes épreuves et le texte des placards avant correction, il était possible en effet, par «soustraction », de reconstituer les transformations opérées par Proust sur ces placards. Voir F. Leriche, thèse citée, t. I, p. 224-230 et t. II, tableau des additions p. 100-108.

FrançOISE Leriche, ancienne assistante de Philip Kolb à l'Université d'Urbana-Champaign (Illinois), enseigne actuellement à l'Université de Grenoble. Spécialiste de la correspondance de Proust, de la genèse de l'œuvre, et des problématiques de l'édition numérique, elle a récemment publié une réédition anthologique de la Correspondance (Lettres 1879-1922, Plon, 2004), collaboré à l'édition du Cahier 26 (BnF/Brepols, 2010), et coordonné avec Alain Pagès le volume Genèse et correspondances (EAC, 2012). Elle codirige la collection « La Fabrique de l'œuvre » aux ELLUG.

francoise.leriche@wanadoo.fr 


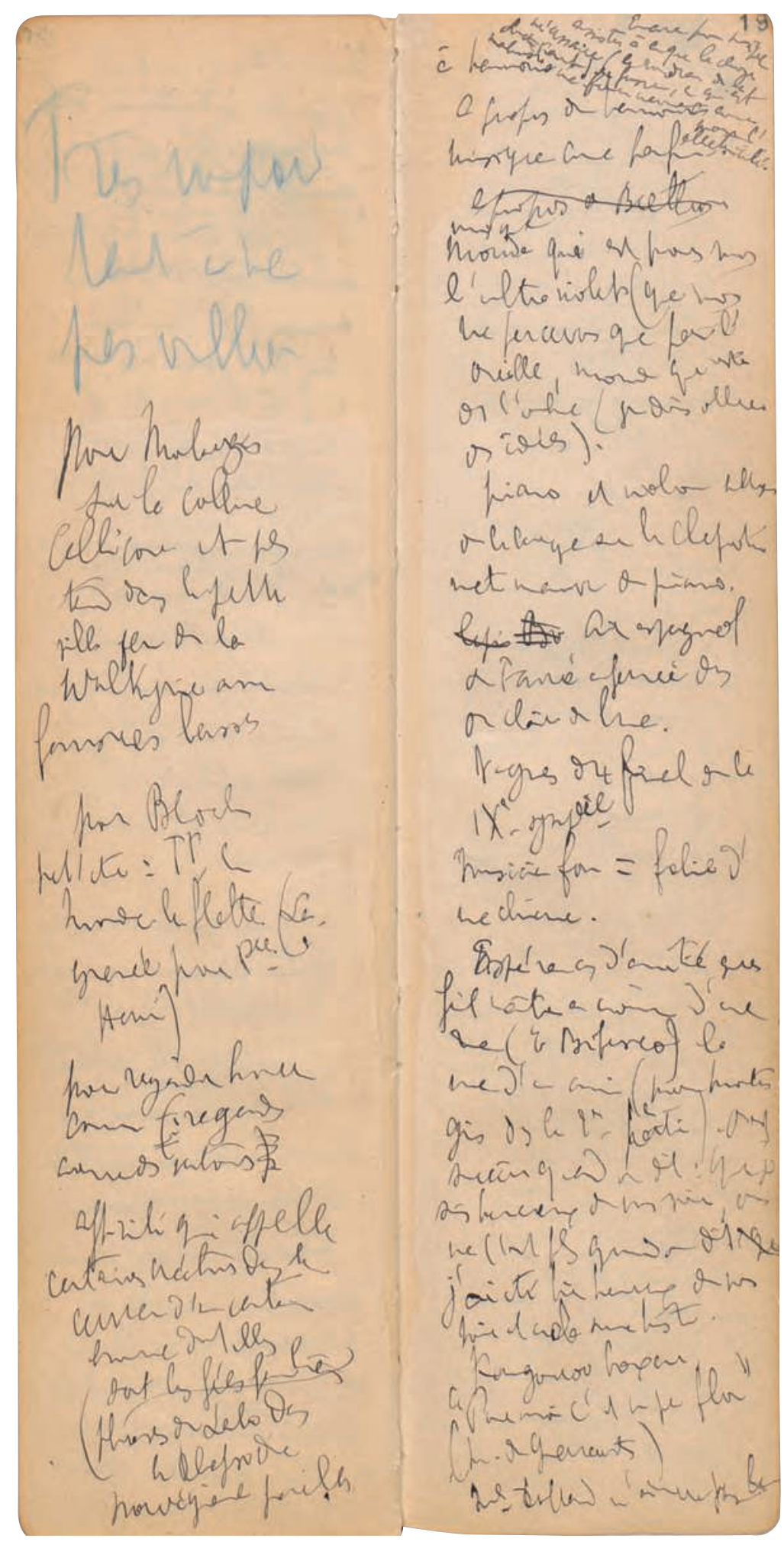

Fig. 1 : Carnet 2, fos $18 \mathrm{v}^{\mathrm{o}}-19 \mathrm{r}^{\mathrm{o}}$

(BnF, NAF 16638) 
Très impor-

tant à ne

pas oublier

\section{Pour Montargis \\ sur la colline \\ Callicore et plus}

tard dans la petite

ville feu* de la

Walkyrie avec

fameuses basses

pour Bloch

peut'être : ' $\mathrm{T}^{\mathrm{t}}$ le

monde le flatte (La-

grenée pour Pce

Henri)

pour regarder homme

connu $f$ : regards

comme des ventousesf

affinité qui appelle

certaines créatures dans le cerveau d'un certain

homme dont elles

sont les fées familières

(phrases de Lalo dans

la Rhapsodie

norvégienne pareilles
Encore pour musique
assister à ce que lo nécessaire à que la chose Sonate Franck) se (le rondeau de la à Namouna.) force inconnue com est
À propos de Namouna 'pourl' musique comme parfum. A propos de Beethoven monde qui est pour nous l'ultaviolet (que nous ne percevons que par l' oreille, monde qui reste $\mathrm{d}[\mathrm{an}] \mathrm{s}$ l'ombre (je dois oublier des idées).

piano et violon sillage de la barque sur le clapote ment mauve du piano. te pi Be Air espagnol de Fauré enfermé dans du clair de lune.

Vagues du final de la $\mathrm{IX}^{\mathrm{e}}$ symphie

Musicien fou $=$ folie d' une chienne.

Espérances d'amitié que fait naittre au coin d'une rue (E Bibesco) la vue d'un ami (pour Montar gis dans la $2^{\mathrm{e}}$ partie). On est sincère quand on dit: Que je suis heureux de vous voir, on ne l'est plus quand on dit सQue j'ai été bien heureux de vous voir et cela sonne triste.

Kangourou boxeur «Pour moi c'est un peu flou » (M. de Guermantes) Me Cottard n'aime pas la 


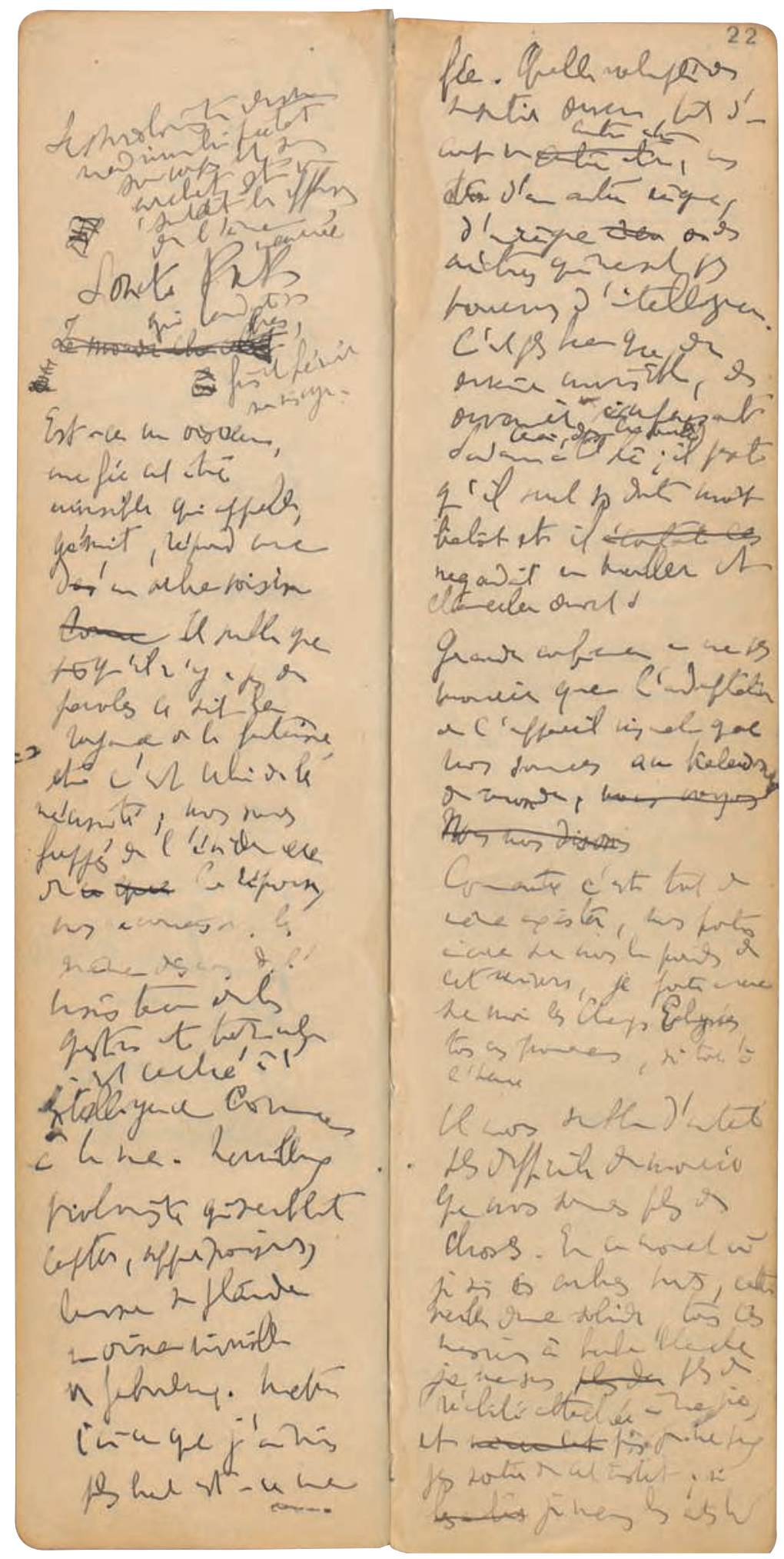

Fig. 2 : Carnet 2, fos $21 \mathrm{v}^{\mathrm{o}}-22 \mathrm{r}^{\mathrm{o}}$ (BnF, NAF 16638) 


\begin{tabular}{|c|c|}
\hline 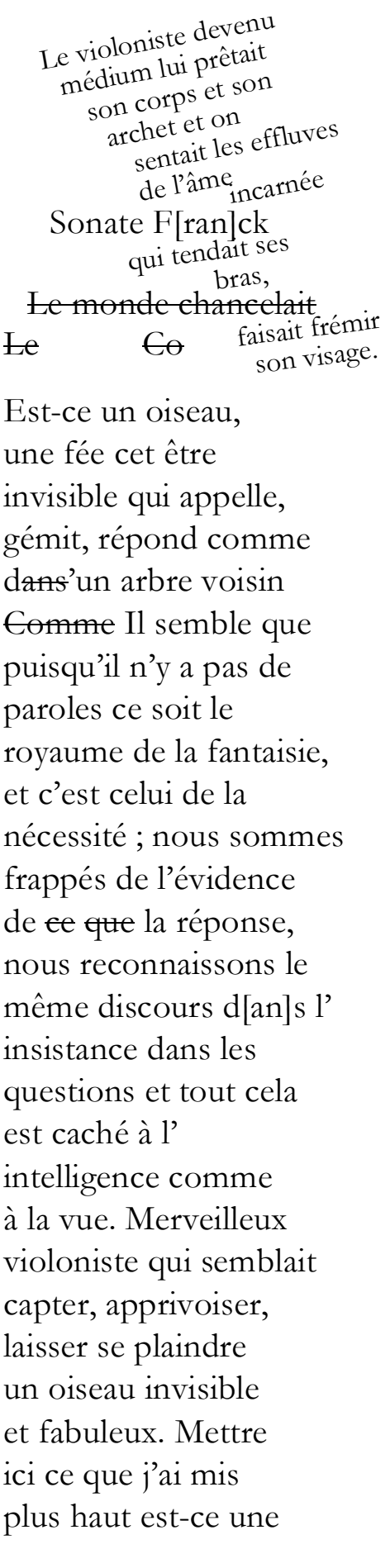 & $\begin{array}{l}\text { fée. Quelle volupté de } \\
\text { se sentir devenu, tout d'un } \\
\text { autre être } \\
\text { coup un autre être, un } \\
\text { être d'un autre règne, } \\
\text { d'un règne rem ou des } \\
\text { créatures qui ne sont pas } \\
\text { pourvues d'intelligence. } \\
\text { C'est plus beau que de } \\
\text { devenir invisible, de } \\
\text { devenir u impuissant* } \\
\text { Ceci dans la soirée } \\
\text { Swann était là ; il pensait } \\
\text { qu'il serait ss doute mort } \\
\text { bientôt et il éceutait ces } \\
\text { regardait se troubler et } \\
\text { chanceler devant s } \\
\text { Grande confiance en ne pas } \\
\text { mourir que l'adaptation } \\
\text { de l'appareil visuel que } \\
\text { nous sommes au kaléidoscope } \\
\text { du monde, nous croyons* } \\
\text { Aous nous disøns } \\
\text { Connaittre c'est tout de } \\
\text { même exister, nous portons } \\
\text { encore sur nous le poids de } \\
\text { cet univers, je porte encore } \\
\text { sur moi les Champs Élysées, } \\
\text { tous ces promeneurs, si tout à } \\
\text { l'heure } \\
\text { Il nous semble d'autant } \\
\text { plus difficile de mourir } \\
\text { que nous sommes plus de } \\
\text { choses. En ce moment où } \\
\text { je suis ces arbres verts, cette } \\
\text { vieille dame solide, tous ces } \\
\text { messieurs à barbe blanche } \\
\text { je me sens plus de plus de } \\
\text { réalité attachée à ma vie, } \\
\text { et même cet puis je ne peux } \\
\text { pas sortir de cet instant ; si } \\
\text { lesautres je meurs les autres le }\end{array}$ \\
\hline
\end{tabular}



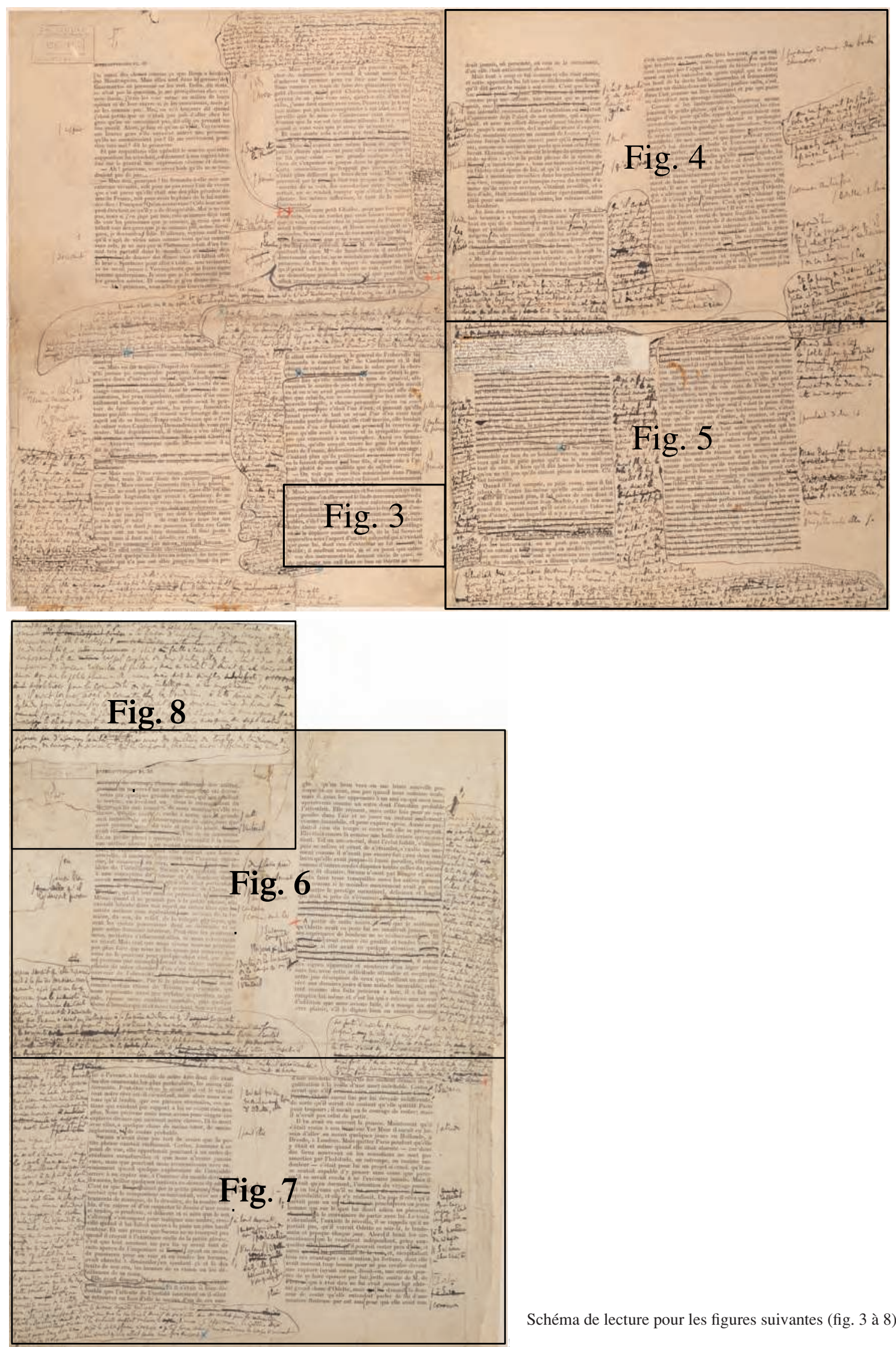
Mais le concert recommença et Swam comprit qu'ilne pourrait pas s'en aller avant la fin de nouveau numéro du programme. Il souffrait de rester enfermé au milieu de ces gens dont la bêtise et les ridicules le frappaient d'autant plus douloureusement qu'ignorant son amour, incapables, s'ils l'avaient connu, de s'y intéresser et de faire a) chose que d'en sourire commed'un enfantillage ou de le déplorer comme une folie, ils le lui faisaient apparaître sous l'aspect d'un état subjectif qui n'existait que pour lui, dont rien d'extérieur ne lui asensent/ la Níalité; il souffrait surtout, 11. son des instruments lui donnait envie de crier, 4 de prolonger son exil dans ce lieu où Odette ne vien- 


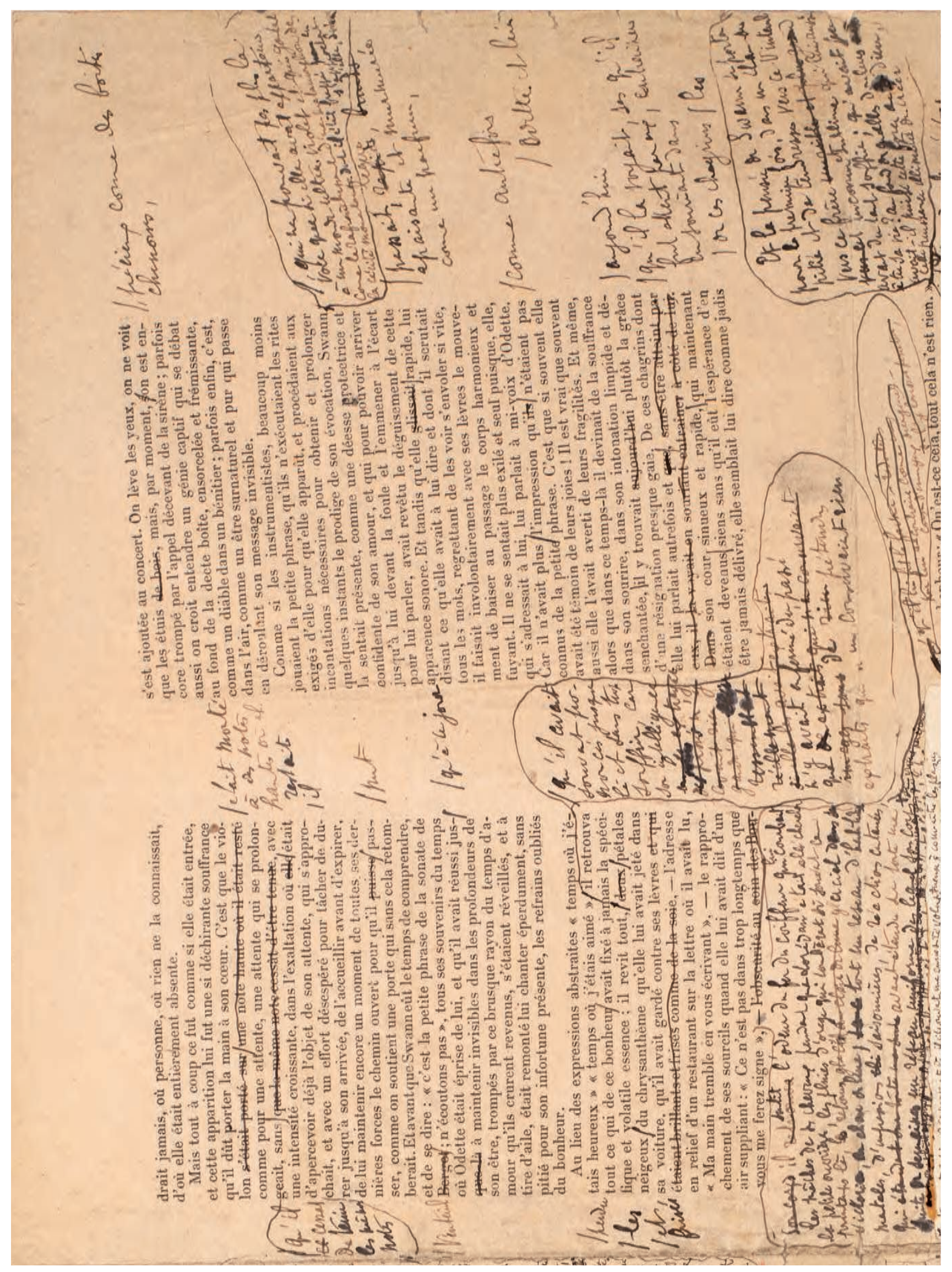




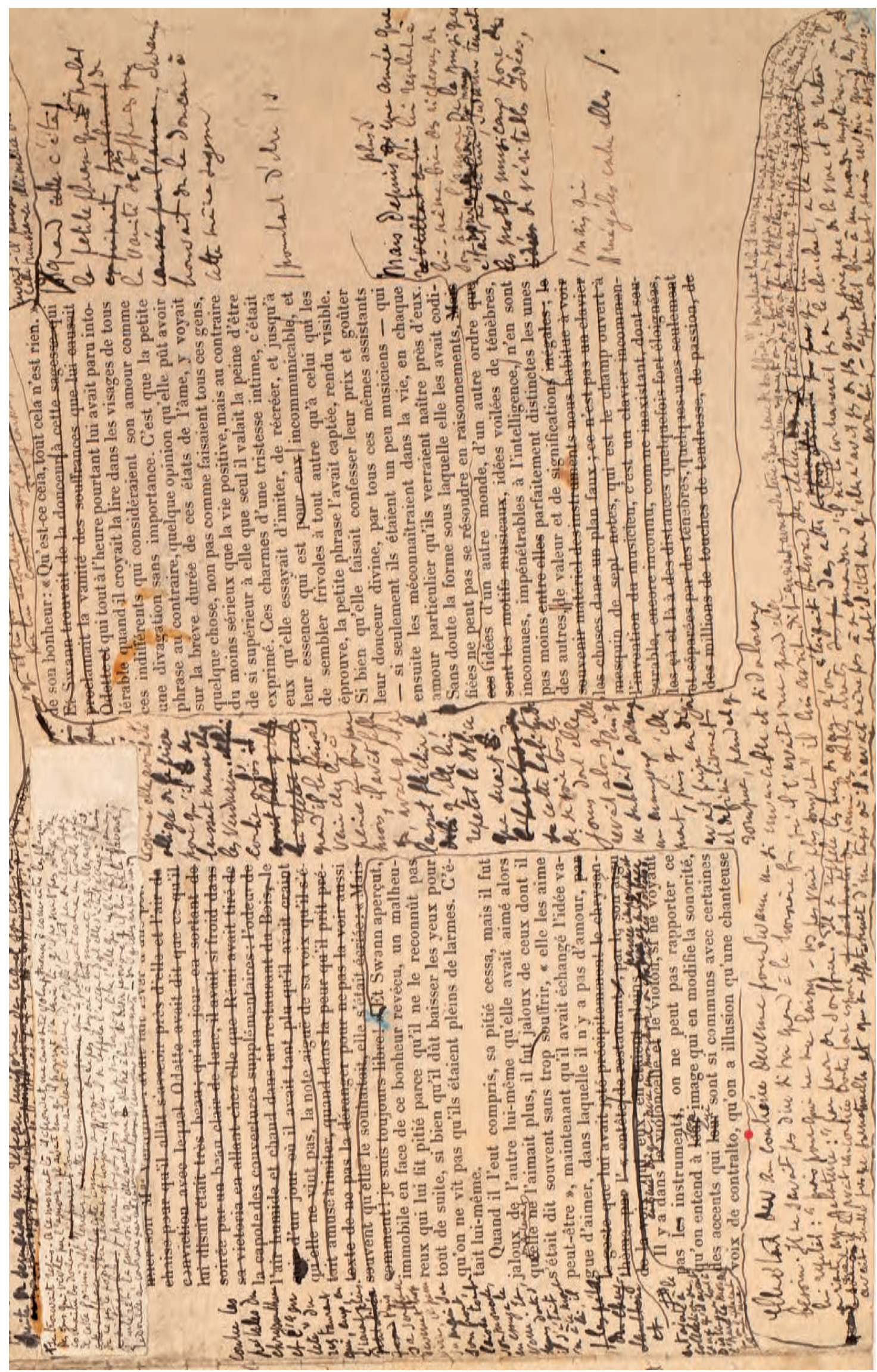

Fig. 5 : Placard Bodmer n ${ }^{\circ} 49$, col. 6 et 8

[Fondation Martin Bodmer, Cologny (Genève)] 


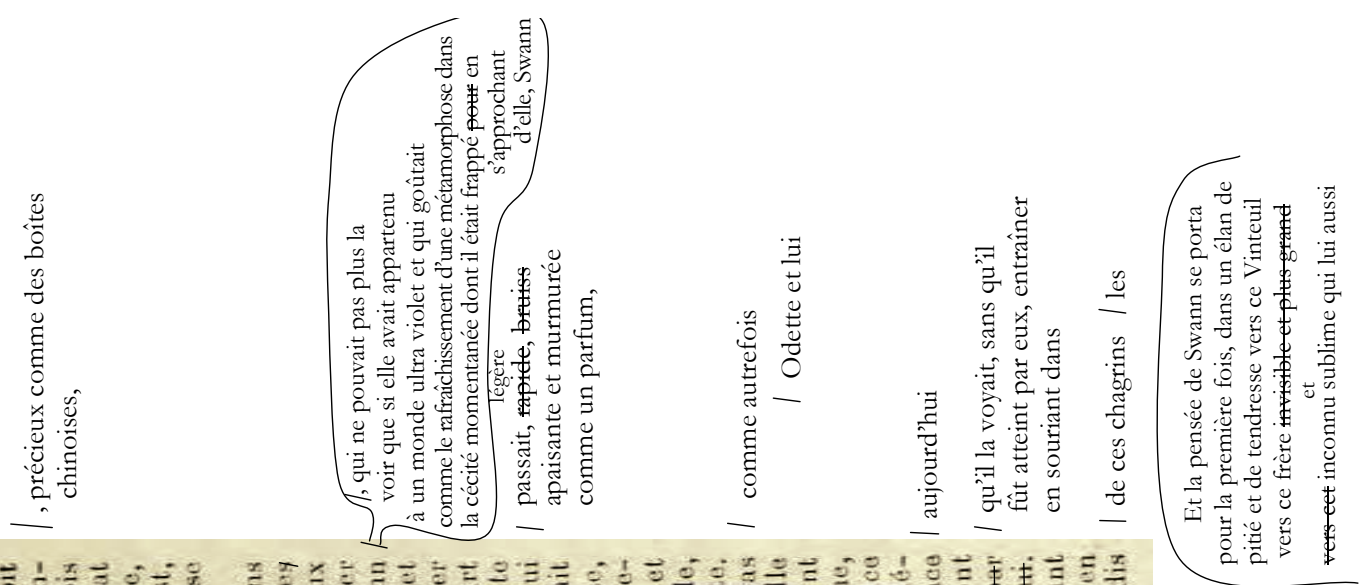

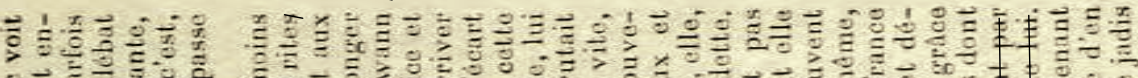

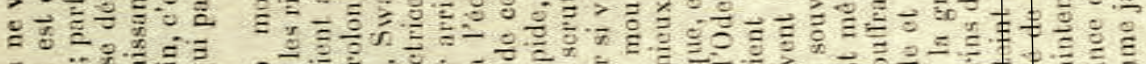
б

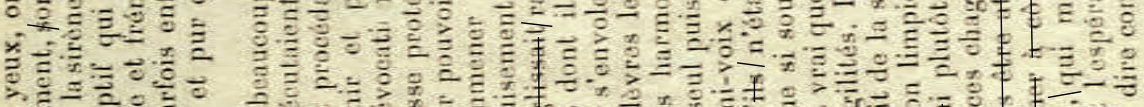

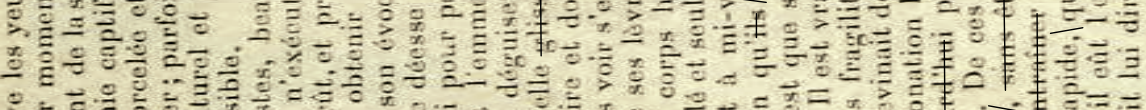

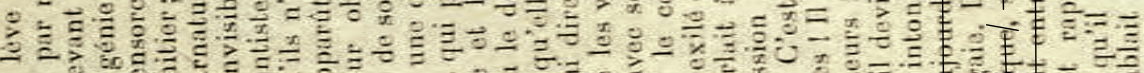
○.j.

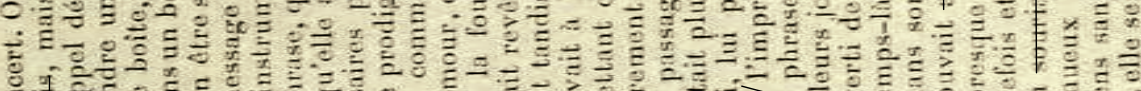

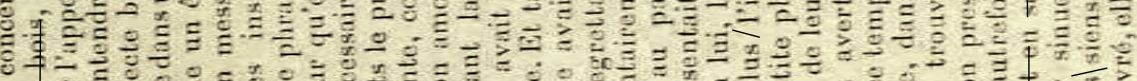

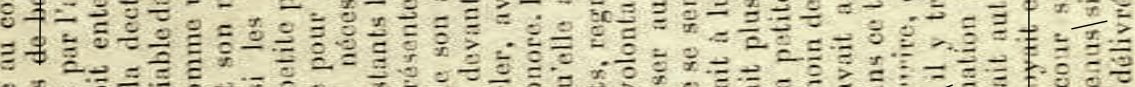

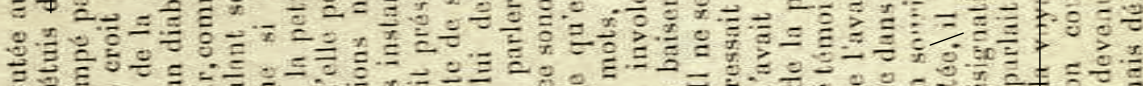

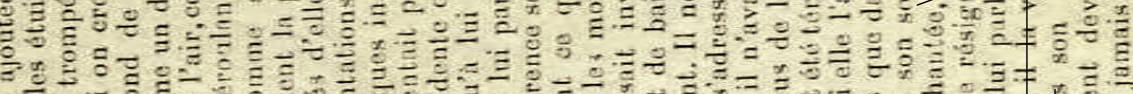
Whำ
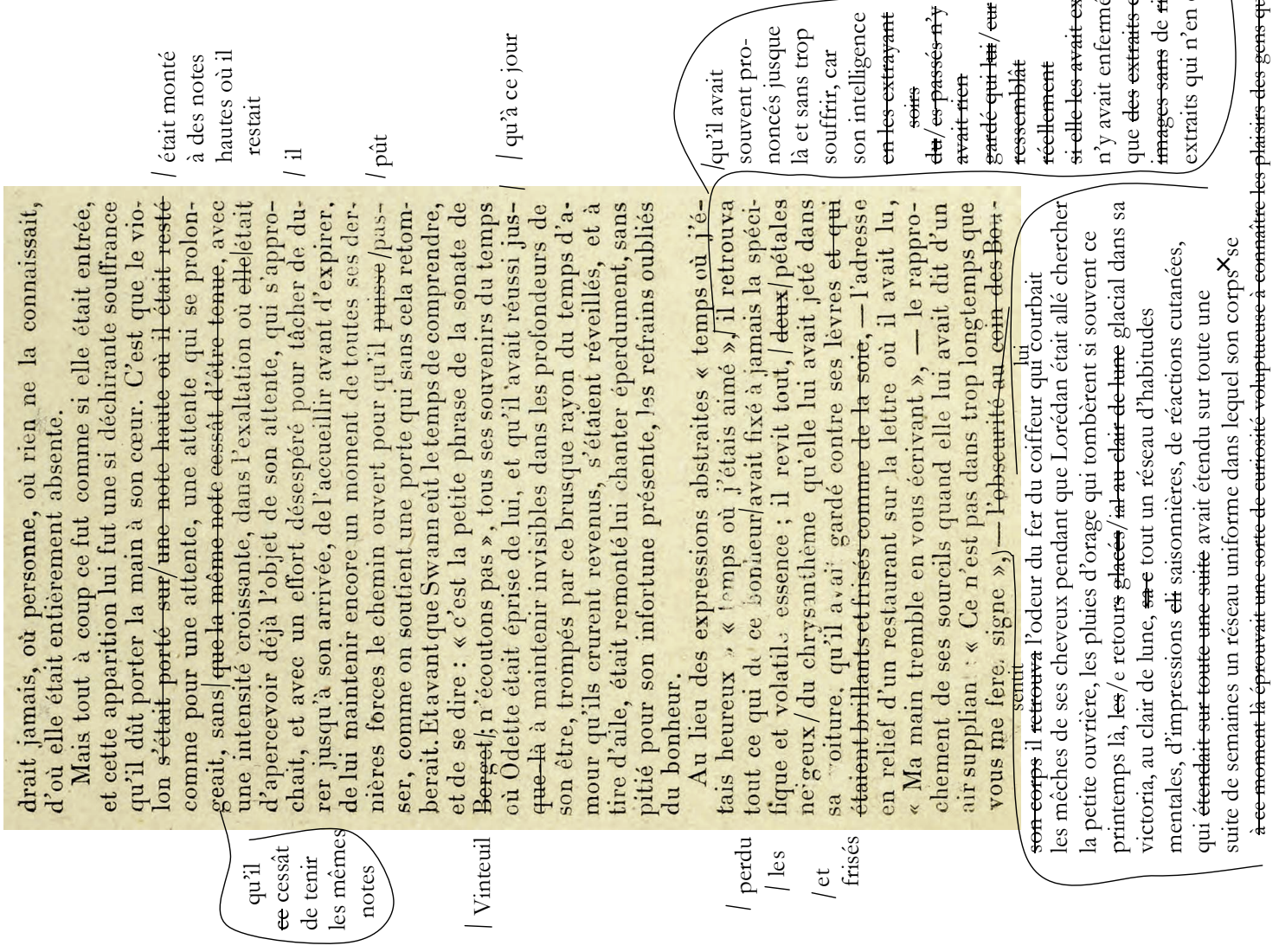

害

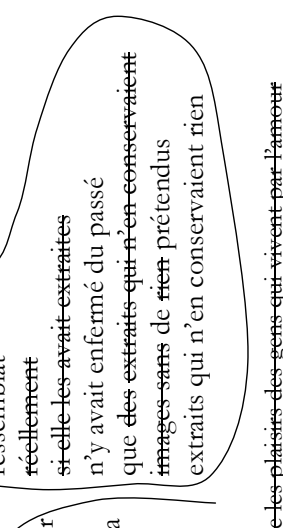




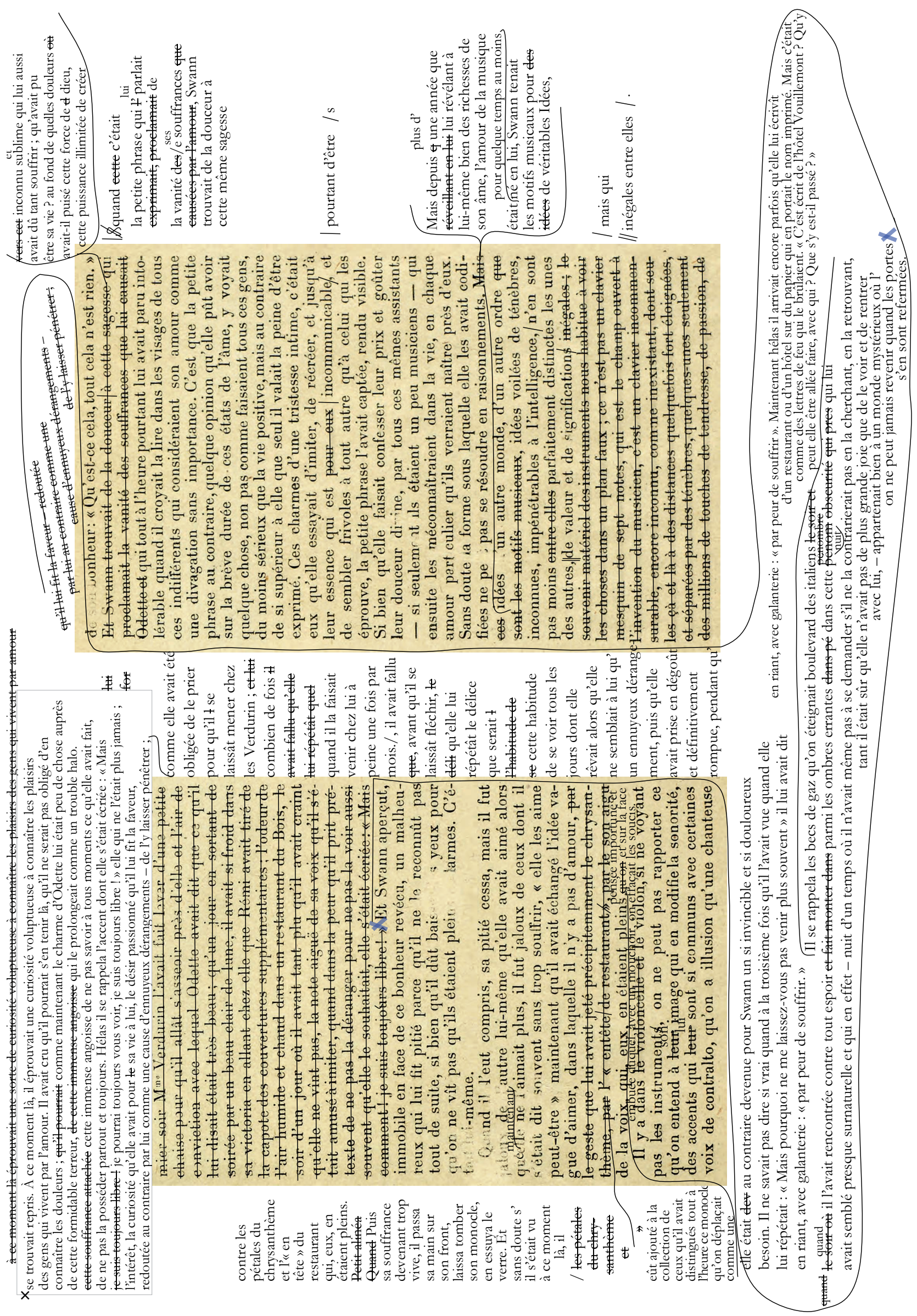

127 


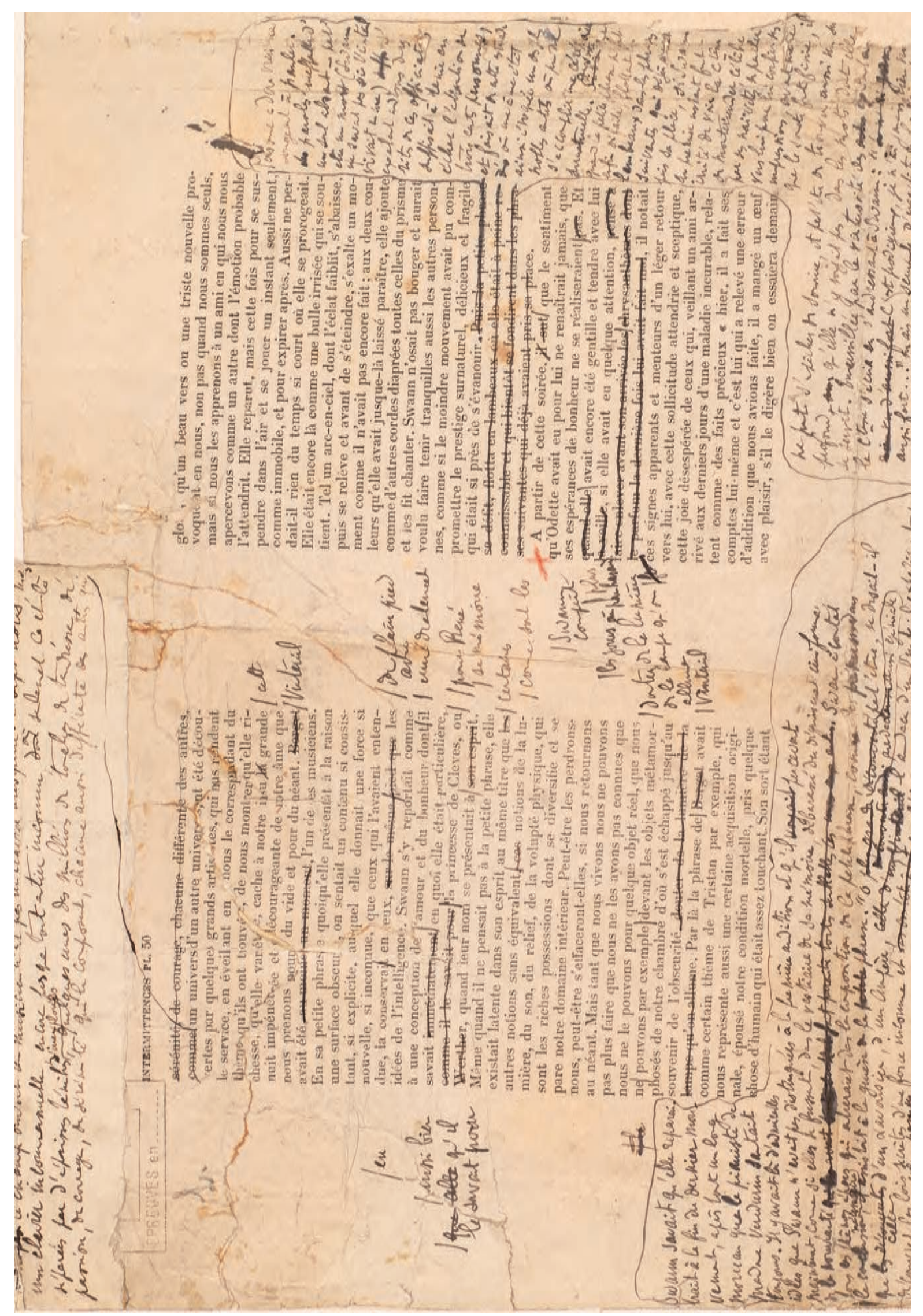




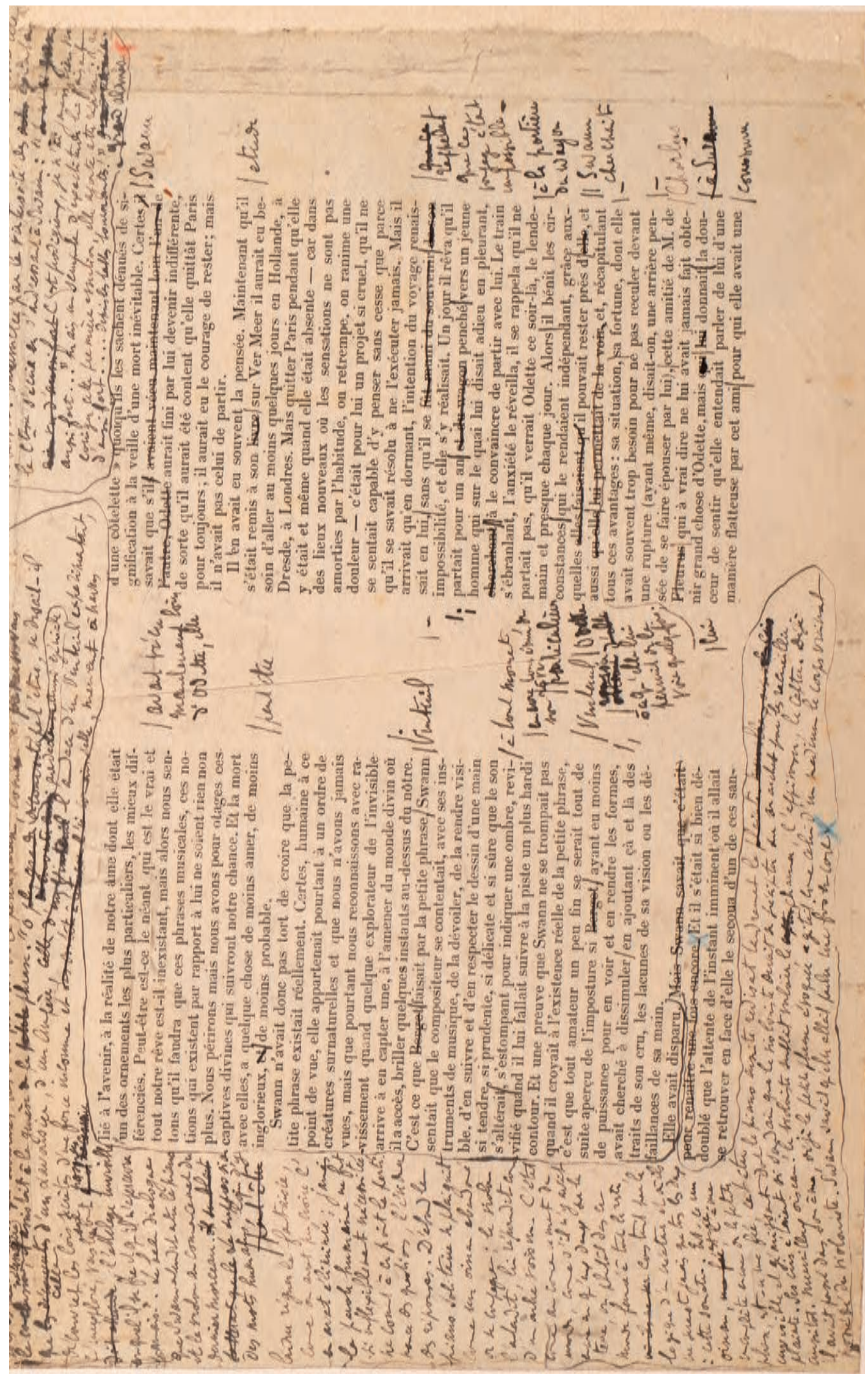




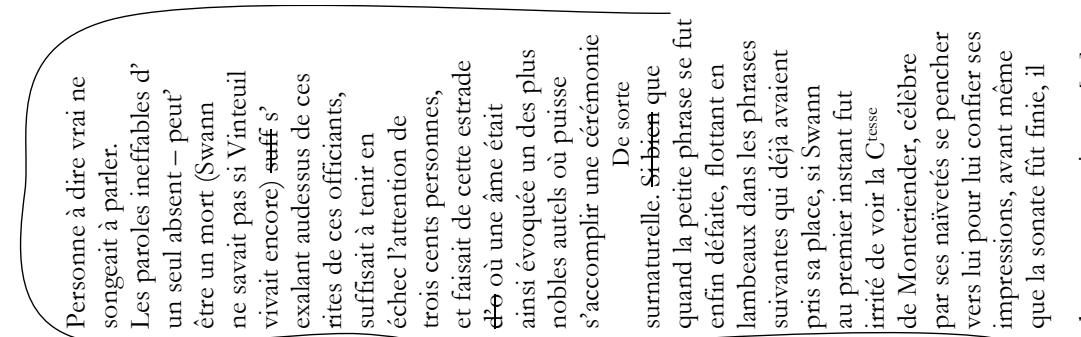

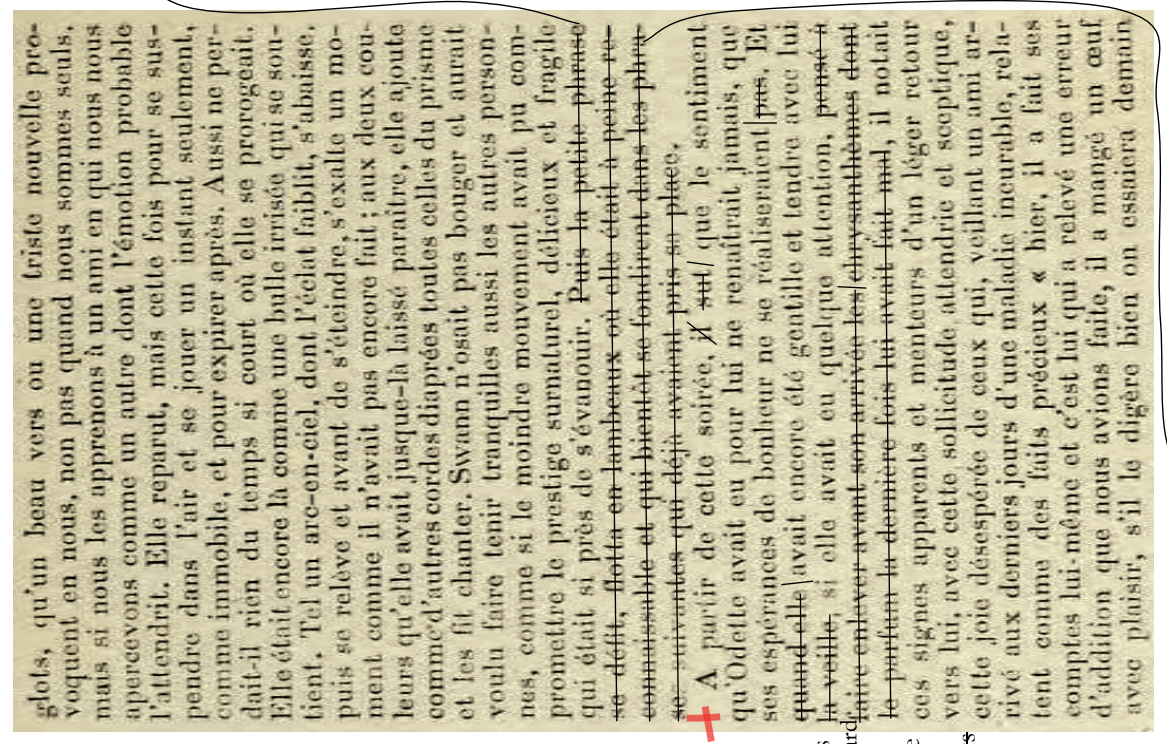

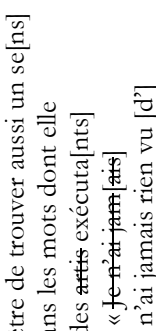

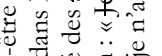

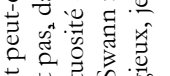

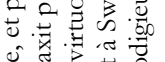

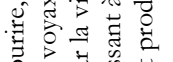

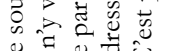

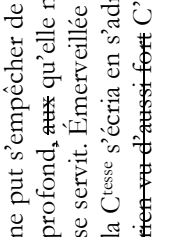

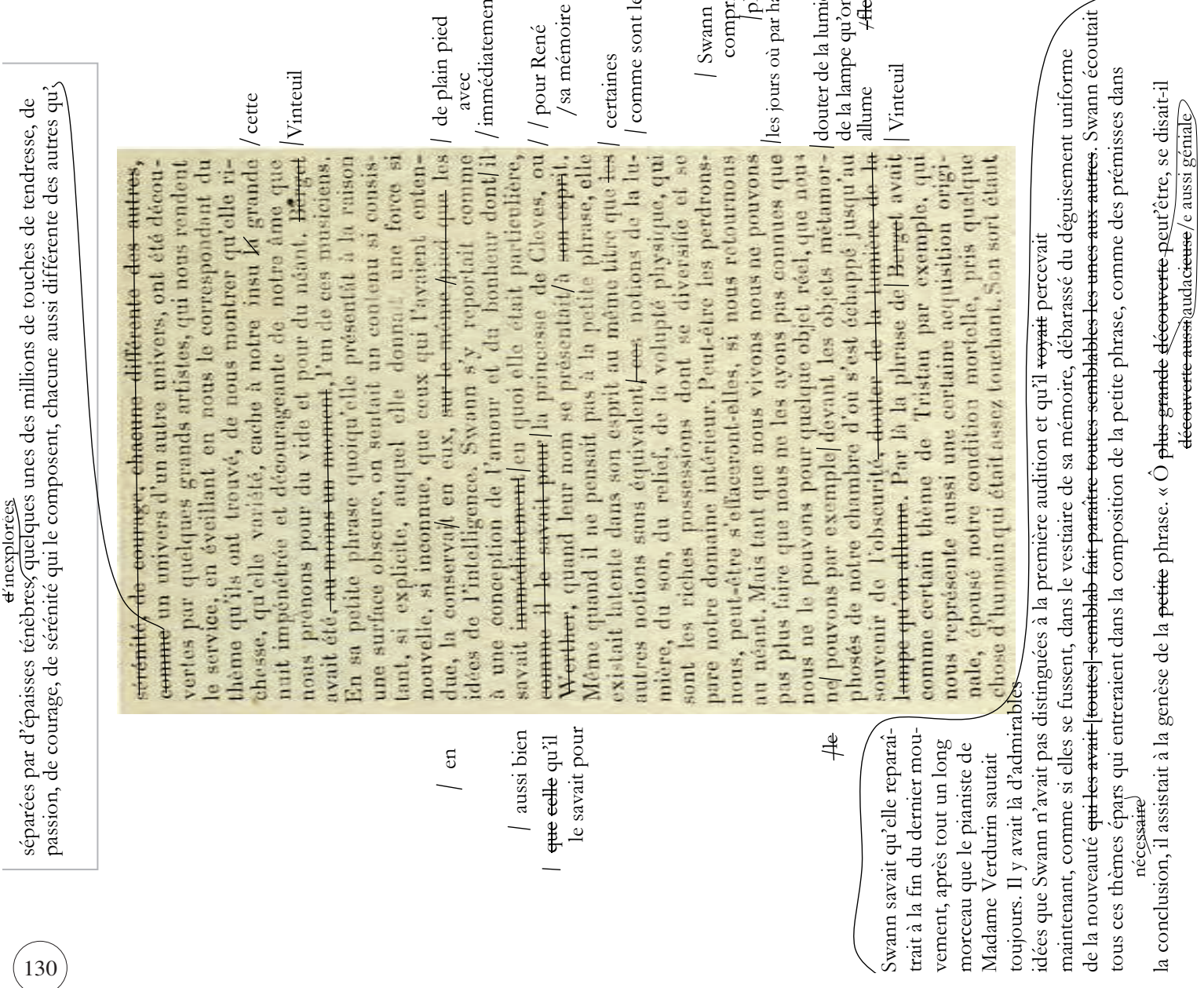




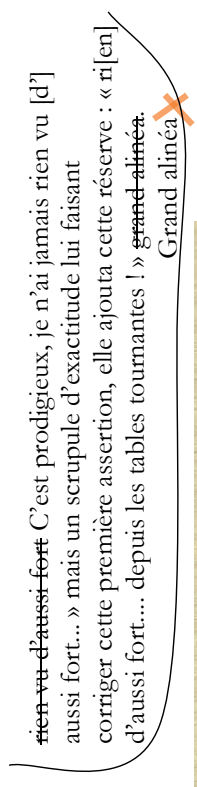

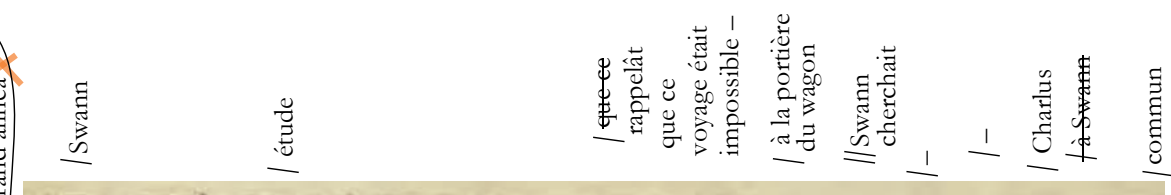

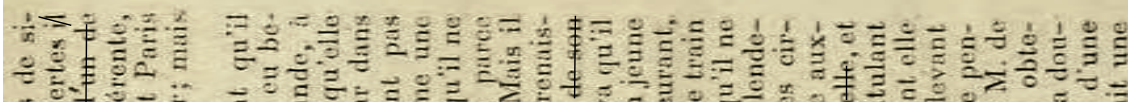
3ư 解事.

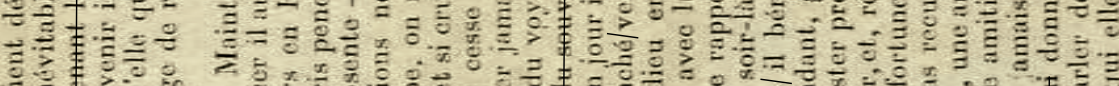

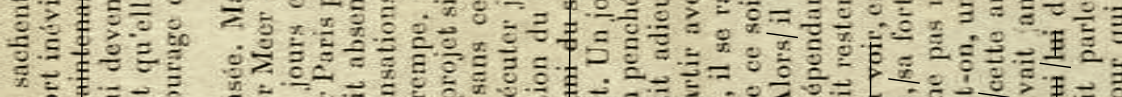

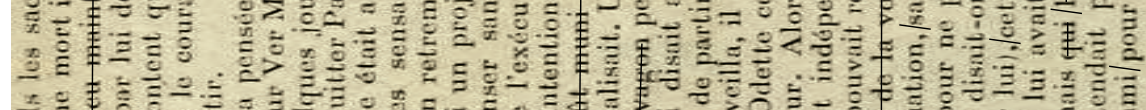

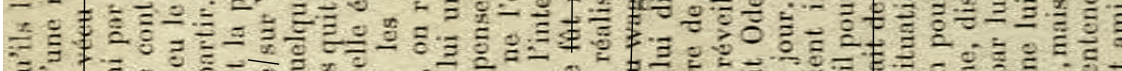

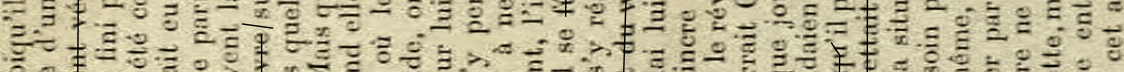

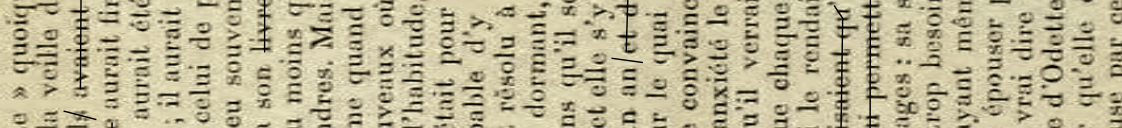

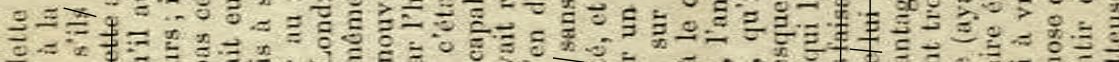
8.

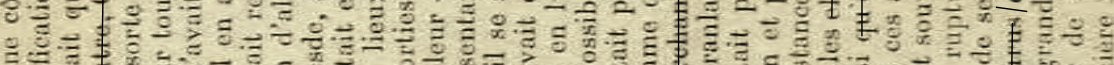

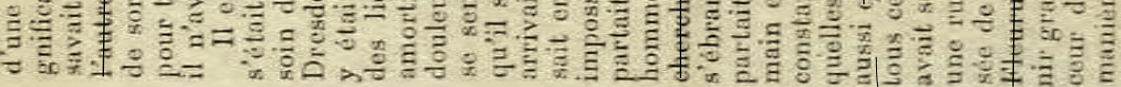

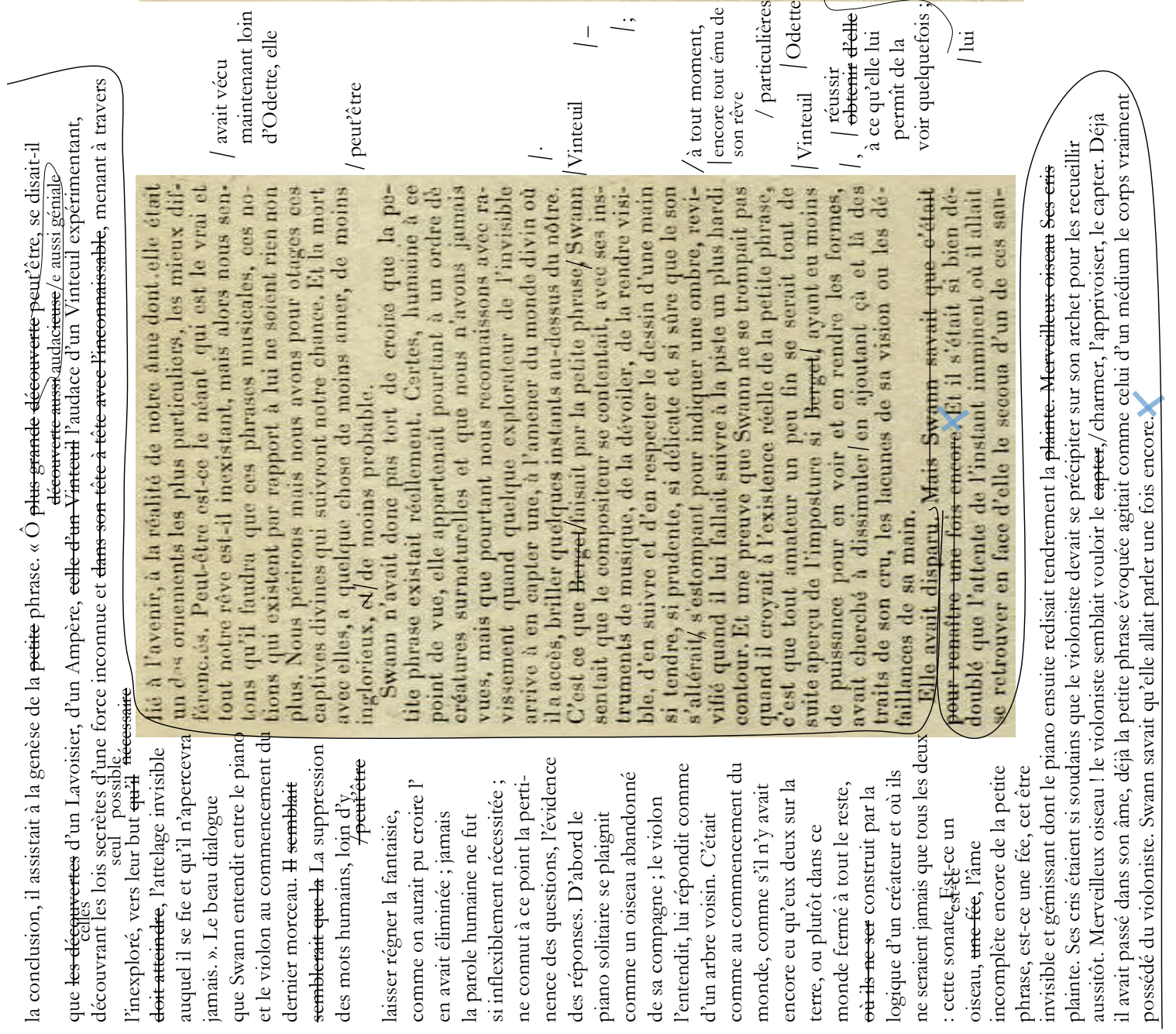




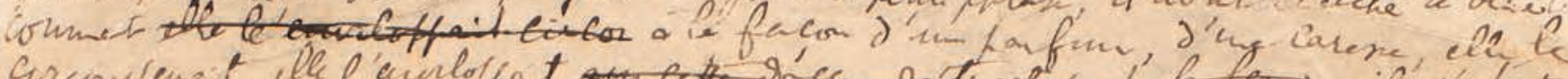

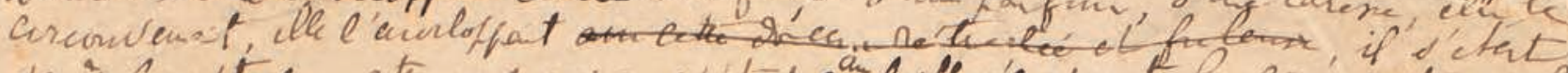

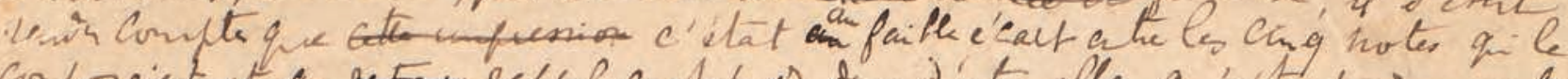

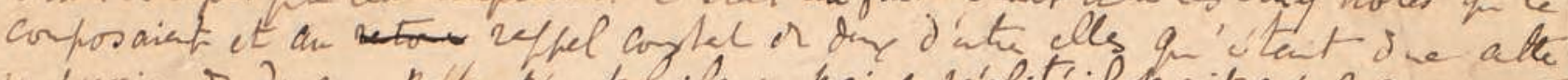

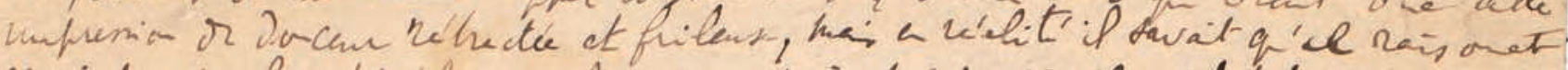

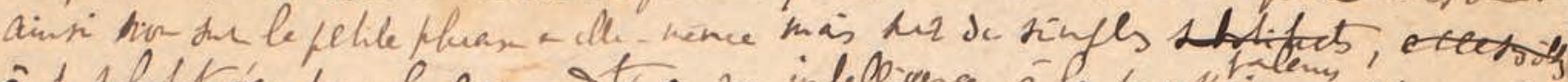

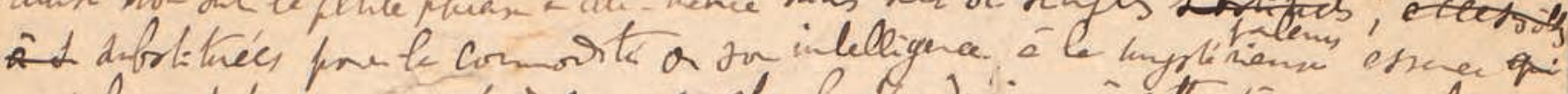

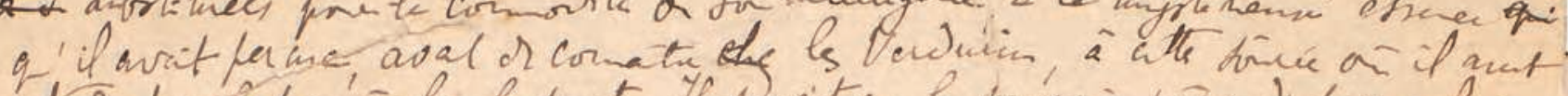

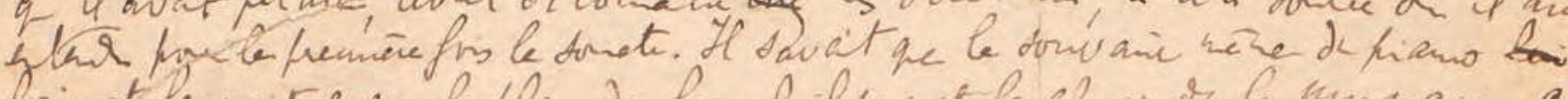

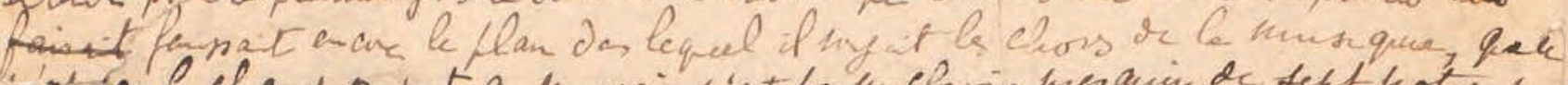

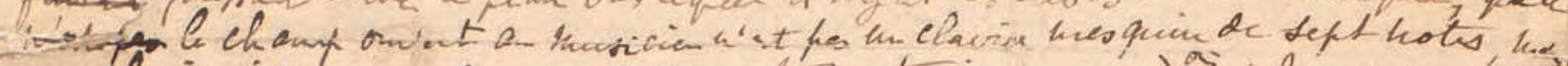

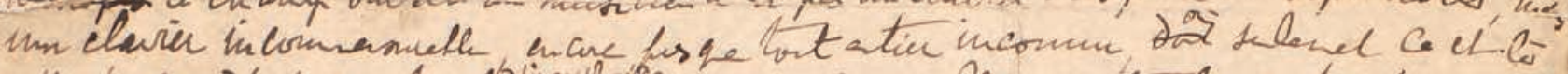

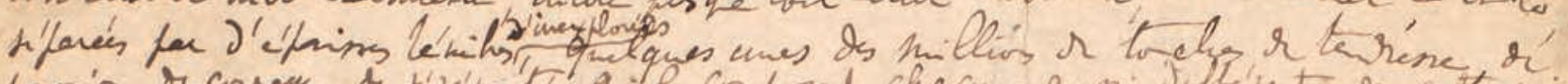

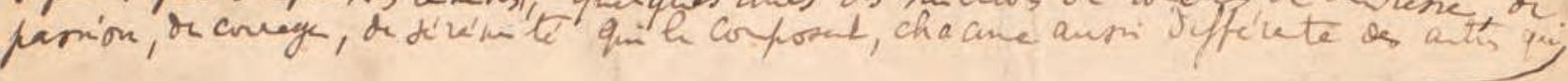

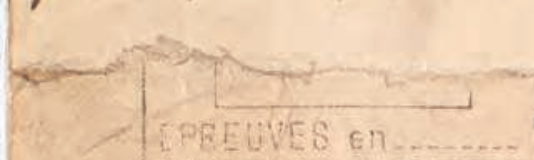

INTERMITTENGES PL, 50

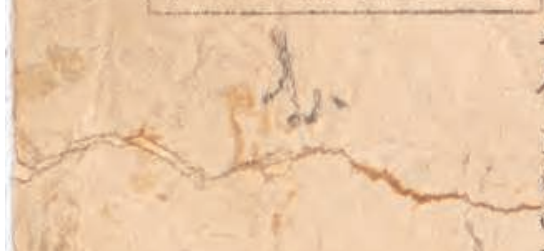

sórénitif de courage, chacune différente des autres. commel un univers d'un autre universo, nt été décourertes par quelques grands artic stes, qui mas rendent le service, en éveilant en nous le corresppidant du thimorqu'ils ont thouvóc, de nous montrenqu'elle rinuit impénênée et évécouche à notre insu da grande / w nous prenons pour du vide et pour du néant. àme que / Virléril En sa petite phras/ a quoiqu'ell, l'un de es musiciens. une surface obscris on sentait présentât à la raison

Fig. 8 : Placard Bodmer ${ }^{\circ} 50$, paperole [Fondation Martin Bodmer, Cologny (Genève)] 
Quand après la soirée Verdurin, se faisant rejouer la petite phrase, il avait cherché à démêler comment elle t'enveloppait cireo à la façon d'un parfum, d'une caresse, elle le circonvenait, elle l'enveloppait avec cette douceur rétractée et frileuse, il s'était rendu compte que eette impression c'était au faible écart entre les cinq notes qui la composaient et au rappel constant de deux d'entre elles qu'était due cette impression de douceur rétractée et frileuse, mais en réalité il savait qu'en/il raisonnait ainsi non sur la petite phrase en elle-même mais sur de simples substituts, accessibles às substituées pour la commodité de son intelligence à la mystérieuse essence qui qu'il avait perçue, avant de connaitre ehez les Verdurin, à cette soirée où il avait entendu pour la première fois la sonate. Il savait que le souvenir même du piano tui faisait faussait encore le plan dans lequel il voyait les choses de la musique, que ce n'est pas le champ ouvert au musicien n'est pas un clavier mesquin de sept notes, mais un clavier incommensurable, encore presque tout entier inconnu, doùt seulement çà et là, d'inexplorées séparées par d'épaisses ténèbres, quelques unes des millions de touches de tendresse, de passion, de courage, de sérénité qui le composent, chacune aussi différente des autres qu'

sérénité de courage, chacune différente des autres, comme un univers d'un autre univers, ont été découvertes par quelques grands artistes, qui nous rendent le service, en éveillant en nous le correspondant du thème qu'ils ont trouvé, de nous montrer qu'elle richesse, qu'elle variété, cache à notre insu l/a grande nuit impénétrée et décourageante de notre âme que nous prenons pour du vide et pour du néant. Bêrọet/Vinteuil avait été, au moins un moment, l'un de ces musiciens. En sa petite phrase quoiqu'elle présentàt à la raison une surface obscure, on sentait un contenu si consis- 